\title{
Age related changes in clinicopathologic features of oral squamous cell carcinoma (OSCC) in Iranian patients: An epidemiologic study
}

\author{
Ramin Ghafari ${ }^{1}$, Noushin Jalayer Naderi ${ }^{2 *}$, Amirnader Emami Razavi ${ }^{3}$
}

1. Faculty of Dentistry, Shahed University, Tehran, Iran

2. Department of Oral and Maxillofacial Pathology, Faculty of Dentistry, Shahed University, Tehran, Iran

3. Iran National Tumor Bank, Cancer Biology Research Center, Cancer Institute of Iran, Tehran University of Medical Sciences, Tehran, Iran

*Corresponding author:Tel: +98 2188959210 Fax: +98 2188967618

Address: Department of Oral and Maxillofacial Pathology, Faculty of Dentistry, Shahed University, Tehran,

Iran

E-mail: jalayer@shahed.ac.ir

Received; 2018/04/12 revised; 2018/05/14 accepted; 2018/06/14

\section{Abstract}

Introduction: Clinicopathologic characteristics of oral Squamous cell carcinoma (OSCC) affected by age, although it is controversial. In this study the differences in clinicopathological features of OSCC were compared between patients younger and older than 40 years' old.

Materials and methods: In this retrospective study the histopathologic records of OSCC patients who underwent surgery in Cancer Institute of Iran during 2005-2015 were retrieved. The demographic and histopathologic features of patients in two groups of younger than 40 and older than 40 years old were recorded and descriptive analysis was used for statistical interpretation between groups.

Results: The most cases of OSCC in both groups was registered in males with $14.3 \%$ and $85.7 \%$ of cases in younger and older than 40 , retrospectively. Tongue was the most prevalent anatomic location of OSCC in both groups (39\%). Based on clinicopathologic features, most prevalent pathologic degree of OSCC in younger aged patients was moderately differentiated OSCC (14.5\%). In patients older than 40, well differentiated OSCC (87.7\%) was more prevalent.

Conclusion: Based on histopathologic features, the moderately differentiated and well differentiated OSCC were more in younger and older patients than 40, respectively. The finding suggests that OSCC has more malignant feature in young patients.

Keywords: Squamous cell carcinoma, Oral cavity, Prognosis

\section{Introduction}

More than $90 \%$ of oral cancers are squamous cell carcinoma. Patients with oral squamous cell carcinoma (OSCC) commonly are older men in sixth to seventh decade of life. It has been reported that the incidence of OSCC increased with age in recent years (1). Commonly, OSCC is an elder aged group disease. Recent reports showed $0.4 \%$ to $3.9 \%$ prevalence of OSCC in patients younger than 40 years old (2). The prognosis and aggressiveness of OSCC is worsen in patients under 40 years (3-5). Tobacco smoking, viral infection and immunosuppression are

Copyright (C) 2018 Journal of Basic Research in Medical Science. This is an open access article distributed under the terms of the Creative Commons Attribution 4.0 International License (https://creativecommons.org/licenses/by/4.0/) which permits copy and redistribute the material, in any medium or format, provided the original work is properly cited. 
among etiologic factors of OSCC (1). Regard to changing parameters of life style, the impact of traditional etiologic factors in OSCC prevalence has changed. Based on reports, age affects the clinicpathologic parameters of OSCC (6).Our knowledge about the effect of age on the clinic-pathologic status of patients in Iran is very scant and controversial. The aim of study was to compare the clinic-pathologic features of oral squamous cell carcinoma between patients younger and older than 40 years' in Iran.

\section{Materials and methods}

The study was approved by ethical committee of Shahed University under IR.Shahed.REC.1396.55 registration number. The study was cross sectional, retrospective research. The study completed with archive review method. All histopathologic records of patients with pathologic diagnosis of OSCC were retrieved from Iran National Tumor Bank, Cancer Institute, Tehran, Iran during 2005 to 2015. OSCC cases with complete demographic and histopathologic report were included the study. The information of demographic (age, gender and anatomic location) and histophatologic features (degree of histopathologic differentiation, lymph node involvement and tumor size) were extracted from the reports and registered. The subjects were classified in two groups. Group 1: cases younger than 40 years and group 2: cases older than 40 years (6). Distribution of demographic and histopathologic features were obtained based on the patient's age.

\section{Statistical analysis}

The descriptive analysis was used for statistical interpretation. The SPSS software version 19 for Windows (SPSS Inc., IBM Co., Chicago, USA) was used for statistical analyses. The level of significance was set at $\mathrm{P}<0.05$.

\section{Results}

A total 583 cases of OSCC were registered. In patients under 40 , the age range was from 15 to 40 years old. The age range of patients older than 40 was 40 to 93 years old. The most cases of OSCC in both age group was registered in males with $14.3 \%$ and $85.7 \%$ of all cases in younger and older 40, retrospectively. Tongue was the most prevalent anatomic location of OSCC in younger and older 40 years old patients $(18.7 \%$ and $81.3 \%$, retrospectively).Distribution of subjects according to demographic features showed in Table 1. Based on clinicopathologic features, most prevalent pathologic degree of OSCC in younger aged patients was moderately differentiated OSCC $(14.5 \%)$.The well differentiated OSCC $(87.7 \%)$ was more prevalent in patient older than 40. In groups, the tumor size and distribution of lymph node involvement were the same (Table 2).

\section{Discussion}

The study showed that the gender and location of OSCC in patients younger and older than 40 was the same. In both groups, OSCC was more in males and tongue. Based on histopathologic features, the moderately differentiated OSCC were more in younger patients. The well differentiated OSCC was more prevalent in older patients than 40 years.

More than $90 \%$ of OSCC occurs in people older than 40 years of age. Some studies have shown that the incidence of OSCC in young patients is increasing. In people younger than 40 years of age, an incidence of 1 to $6 \%$ has been reported (7). Kapila et al. in a uni-central investigation showed that the incidence of OSCC has increased from $7.7 \%$ in the period from 1990 to 2000 to $11.7 \%$ in the period from 2001 to 2013(6). This finding suggests the changing trend of OSCC in recent years. Changing etiologic factors toward smoking and lifestyle changes can be associated with initiation of carcinoma in youths. 
Table1. Distribution of subjects according to demographic features.

\begin{tabular}{lccc}
\hline & \multicolumn{3}{c}{ Age groups } \\
\cline { 2 - 4 } Variable & $<40$ years & $>40$ years & Total \\
\hline Gender & & & \\
Male & $50(14.3 \%)$ & $298(85.7 \%)$ & $348(100 \%)$ \\
Female & $29(12.3 \%)$ & $206(87.7 \%)$ & $235(100 \%)$ \\
Site of tumor & & & \\
Tongue & $42(18.7 \%)$ & $182(81.3 \%)$ & $224(100 \%)$ \\
Mandible & $11(10.1 \%)$ & $97(89.9 \%)$ & $108(100 \%)$ \\
Lip & $12(11.5 \%)$ & $92(88.5 \%)$ & $104(100 \%)$ \\
Buccal & $5(10 \%)$ & $45(90 \%)$ & $50(100 \%)$ \\
Mouth floor & $1(3.03 \%)$ & $32(96.97 \%)$ & $33(100 \%)$ \\
Maxilla & $3(9.3 \%)$ & $29(90.7 \%)$ & $32(100 \%)$ \\
Palate & $4(21.05 \%)$ & $15(78.95 \%)$ & $19(100 \%)$ \\
Gingiva & $1(12.5 \%)$ & $7(87.5 \%)$ & $8(100 \%)$ \\
Vestibule & $0(0.0 \%)$ & $5(100 \%)$ & $5(100 \%)$ \\
\hline
\end{tabular}

Table 2. Distribution of subjects according to histopathologic parameters.

\begin{tabular}{lccc}
\hline & \multicolumn{3}{c}{ Age groups } \\
\cline { 2 - 4 } Variable & $<40$ years & $>40$ years & Total \\
Gender & $33(12.3 \%)$ & $234(87.7 \%)$ & $267(100 \%)$ \\
Modl & $36(14.5 \%)$ & $211(85.5 \%)$ & $247(100 \%)$ \\
Poor & $5(13.5 \%)$ & $32(86.5 \%)$ & $37(100 \%)$ \\
Tumor size & & & \\
$0-2$ & $24(16.7 \%)$ & $119(83.3 \%)$ & $143(100 \%)$ \\
$2-4$ & $28(12.3 \%)$ & $200(87.7 \%)$ & $228(100 \%)$ \\
$4-6$ & $19(15.1 \%)$ & $107(84.9 \%)$ & $126(100 \%)$ \\
$>6$ & $2(4.1 \%)$ & $46(95.9 \%)$ & $48(100 \%)$ \\
Lymphatic invasion & & & \\
Yes & $27(14.4 \%)$ & $160(85.6 \%)$ & $187(100 \%)$ \\
No & $52(13.1 \%)$ & $344(86.9 \%)$ & $396(100 \%)$ \\
\hline
\end{tabular}

The present study showed that the incidence of OSCC in males younger and older than 40 was the same. This finding is consistent with previous studies which showed that, at any age, the incidence of OSCC is higher in males $(8,9)$. In Contrast to this results, Razavi and Khalesi showed that the incidence of OSCC in Youngers was higher in males (10). The difference between the two studies can be due to differences in sample size and type of sampling.

The findings showed that the anatomic location of OSCC in younger and older patients was the same. In both groups, tongue was the most common site. This finding is in agreement with previous studies $(11,12)$. Contrast to this finding, alveolar mucosa was the most prevalent site of OSCC in young and old patients in Razavi and Khalesi study (10). The different sampling methods of these studies can be the cause of different results.

The histopathologic feature of samples showed that moderately differentiated OSCC was more in younger than 40. Well differentiated cases were more prevalent in patients older than 40 . This finding is consistent with previous studies $(13,14)$. Contrary, the finding is not in agreement with some reports $(10,15,16)$. Some researchers are in believed that OSCC is more anaplasic in young peoples and have more aggressive behavior (17). This topic can be due to the effect of etiologic factors on more malignant outcome of tumor in youths.

Oncogenes and tumor suppressive genes have a critical effect on the immune system in different ages. It seems that high risk habits such as alcohol consumption and tobacco smoking can effect on this process. 
In present study, the tumor size and lymph node involvement was the same in both age groups. This suggests that despite the increase histopathologic grade of OSCC, there is no difference in the clinical picture of the tumor.

The study was unicentral investigation. To get comprehensive results, multi-central researches in different part of Iran is recommended for future study.

In conclusion, the study showed that the gender and location of OSCC in patients younger and older than 40 was the same.

\section{References}

1. Neville BW, Dam DD, Allen CM, Bouquoct JE. Oral and maxillofacial pathology, 2nd ed. Philadelphia, Pensylvania: W.B. Saunders Company; 2016: 374-389.

2. Cuasumano RJ, Persky MS. Squamous cell carcinoma of the oral cavity and oropharynx in young adults. Head Neck Surg. 1988; 10(4): 229-34.

3. Vargas H, Pitman KT, Johnson JT, Galati LT. More aggressivebehavior of squamous cell carcinoma of the anterior tongue inyoung women. Laryngoscope. $\quad 2000 ; 110 \quad(10$ pt1):1623-6. doi:10.1097/00005537200010000-00009.

4. Kuriakose M, Sankaranarayan M, Nair MK. Comparison of oralsquamous cell carcinoma in younger and older patients in India. Eur J Cancer B Oral Oncol. 1992;28B (2):113-20.

5. Yamazaki $H$, Inoue $T$, Koizumi $M$, Yoshida K, Kagawa K, Shimomi H, et al. Age as a prognostic factor for late localrecurrence of early tongue cancer treated with brachytherapy. Anticancer Res. 1997;17 (6D):4709-12.

6. Kapila SN, Natarajan S, Boaz K. A Comparison of clinicopathologicaldifferences in oral squamous cell carcinoma in patients below and above 40 years of age. $\mathrm{J}$ Clin Diagn Res. 2017; 11(9):ZC46-
In both groups, OSCC was more in males and tongue. Based on histopathologic features, the moderately differentiated OSCC were more in younger patients. The well differentiated OSCC was more prevalent in older patients than 40.Further researches need for correlation between histopathologic grade and age.

\section{Acknowledgement}

The authors thank Mr. Mahdi Jaberi for his kindly assistant in research.
ZC50. doi:
10.7860/JCDR/2017/27828.10600 .

7. Udeabor SE, Rana M, Wegener G, Gellrich NC, Eckardt AM. Squamous cell carcinoma of the oral cavity and the oropharynx in patients less than 40 years of age: a 20-year analysis. Head Neck Oncol. 2012;4:28-34. doi: 10.1186/1758-3284-4-28.

8. Amsterdam JT, Strawitz JG.Squamous cell carcinoma of the oral cavity inyoung patients. J Surg Oncol. 1982; 19(2): 65-8.

9. Falaki F, Dalirsani Z, Pakfetrat A, FalakiA, Saghravanian N, Nosratzehi $\mathrm{T}$, et al. Clinical and histopathological analysis of oral squamous cell carcinoma ofyoung patients in Mashhad, Iran: a retrospective study and review of literature. Med Oral Patol Oral Cir Bucal. 2011; 16(4): e473-e7.

10. Razavi SM, Khalesi S. Clinicopathological differences of oral squamous cell carcinoma amongyounger and older patients. J Clin Exp Pathol. 2017; 7: 316.

11. Fan Y, Zheng L, Mao MH, Huang MW, Liu SM, Zhang J, et al. Survival analysis of oral squamous cell carcinoma in a subgroup of young patients. Asian Pac J Cancer Prev. 2014; 15(20): 8887-91. 
12. Koo K, Barrowman R, McCullough M, Iseli T, Wiesenfeld D. Non-smoking non-drinking elderly females: a clinically distinct subgroup of oral squamous cell carcinoma patients. Int $\mathrm{J}$ Oral Maxillofac Surg. 2013; 42(8): 929-33.doi:

10.1016/j.ijom.2013.04.010.

13. Ur Rahaman SM, Ahmed Mujib B. Histopathological correlation oforal squamous cell carcinoma among younger and older patients. J Oral Maxillofac Pathol. 2014; 18(2): 183-8. doi: 10.4103/0973-029X.140734.

14. Siriwardena BS, Tilakaratne A, Amaratunga EA, Udagama $\mathrm{MN}$, Ogawa I, Kudo Y, et al. Analysis of histopathological and immunohistochemicaldifferences of oral squamous cell carcinoma in young and old patients in Sri Lanka. J Oral Pathol Med. 2017; 36(6): 357-62.

15. Sun Q, Fang Q, Guo S. A comparison of oral squamous cellcarcinoma between young and old patients in a single medical center in China. Int $\mathbf{J}$ Clin Exp Med. 2015; 8(8): 12418-23.

16. Sasaki T, Moles DR, Imai Y, Speight PM.Clinico-pathological features of squamous cell carcinoma of the oral cavity in patients <40years of age. $\mathrm{J}$ Oral Pathol Med. 2005; 34(3): 129-33.

17. Tsukuda M, Ooishi K, Mochimatsu I, Sato H. Head and neck carcinoma in patients under the age of forty years. Jpn J Cancer Res. 1993; 84(7):748-52. 